\author{
UNITED STATES \\ DEPARTMENT OF THE INTERIOR \\ GEOLOGICAL SURVEY
}

\title{
Interfacial contact angle measurements of water, mercury, and 20 organic liquids on quartz, calcite, biotite, and Ca-montmorillonite substrates
}

\author{
Edgar F. Ethington ${ }^{1}$
}

Open-File Report 90-409

July 1990

This report has not been reviewed for conformity with U. S. Geological Survey editorial standards. Any use of trade names is for descriptive purposes only and does not imply endorsement by the U. S. G. S. 


\section{NOTICE}

The information in this document has been funded in part by the United States Environmental Protection Agency under interagency agreement DW14932497-01-1/2 to the United States Geological Survey. It has been subjected to Agency review and approved for publication. Mention of trade names or commercial products does not constitute endorsement or recommendation for use.
Aldo T. Mazzella, Project Officer
Advanced Monitoring Systems Division
U. S. Environmental Protection Agency
Las Vegas, Nevada 89193-3478 


\section{INTRODUCTION}

The literature search during the compilation by Lucius, et al (1989) revealed little published information about contact angles. The purpose of this paper is to make available the measured contact angles of water, mercury, and 20 organic liquids on substrates of quartz, calcite, biotite, and $\mathrm{Ca}-$ montmorillonite.

A small drop of liquid placed on a uniform, perfectly flat, solid surface, will not always spread completely over this surface, but the edge of the drop may make an angle $\theta$ with the solid. Different liquids can exhibit different characteristic contact angles on the same surface. A single liquid can exhibit different characteristic contact angles on different material surfaces. These characteristic contact angles can be used to rank the ability of a liquid to wet, or cover, a substrate and to calculate the capillary pressure.

Capillary pressure is responsible for a liquid's tendency to disperse through a porous medium due to interfacial forces. In a porous medium initially filled with air, the capillary pressure, $\mathrm{p}_{\mathrm{c}}$ in pascals, can be calculated using the equation

$$
\mathrm{p}_{\mathrm{c}}=\frac{2 \sigma_{\mathrm{al}} \cos \theta}{\mathrm{R}} .
$$

Where $\sigma_{\mathrm{al}}$ is the air/liquid surface tension in newtons/meter, $\theta$ is the contact angle in degrees, and $R$ is the capillary tube radius in meters (Bear and Verruijt, 1987). $R$ is an easy value to determine for a capillary tube, but its evaluation for geologic media is complex and beyond the scope of this paper

Three types of contact angle are reported in this paper: sessile, advancing, and receding. For the sessile drop, the contact angle is for a stable non-moving drop on the substrate. For a drop which is expanding, the moving leading edge exhibits the advancing contact angle: $\theta_{\mathrm{a}}$; for a drop which is contracting, the moving trailing edge exhibits the receding contact angle: $\theta_{\mathrm{r}}$. The difference between the magnitude of the advancing and receding contact angles is the hysteresis and describes the higher capillary pressure that may be observed when a medium is drained rather than filled. Figure 1 shows two different types of sessile contact angles: $\theta$ less than $90^{\circ}$ (left) is a substrate wettable by the liquid, and $\theta$ greater than $90^{\circ}$ (right) is a substrate not wettable by the liquid. The smaller a liquid's contact angle on a material, the greater is that liquid's ability to wet that material, and thus, the preferential wettability of one liquid over another on a given material may be ranked. The product of surface tension and the cosine of the contact angle may also be used to rank materials as it is proportional to capillary pressure.
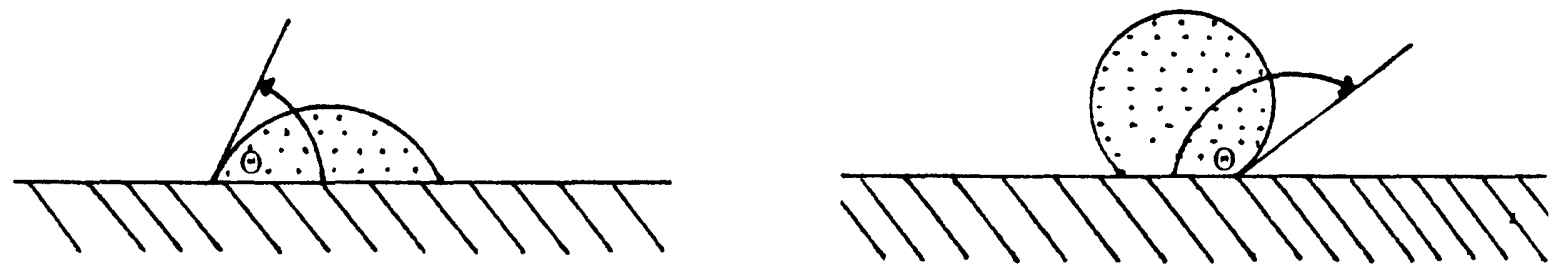

Figure 1. A schematic representation of sessile drops on a smooth, flat surface. The contact angle, $\theta$, is measured through the liquid to a line tangent to the edge of the drop making contact with the substrate. 
CHEMICALS MEASURED

NAME

acetic acid

acetone

aniline

benzene

carbon tetrachloride

chlorobenzene

chloroform

cyclohexane

1, 2-dichlorobenzene

1, 4-dichlorobenzene

ethanol 95\%(denatured)

ethylbenzene

ethylene glycol

mercury

methanol

nitrobenzene

toluene

1, 2, 4-trichlorobenzene (TCB)

water

m-xylene

0 -xylene

p-xylene

\section{CAS RN}

64-19-7

67-64-1

62-53-3

71-43-2

56-23-5

108-90-7

67-66-3

110-82-7

95-50-1

106-46-7

64-17-5

100-41-4

107-21-1

7439-97-6

67-56-1

98-95-3

108-88-3

120-82-1

$7732-18-5$

108-38-3

$95-47-6$

106-42-3
CHEMICAL FORMULA

$\mathrm{C}_{2} \mathrm{H}_{4} \mathrm{O}_{2}$

$\mathrm{C}_{3} \mathrm{H}_{6} \mathrm{O}$

$\mathrm{C}_{6} \mathrm{H}_{7} \mathrm{~N}$

$\mathrm{C}_{6} \mathrm{H}_{6}$

$\mathrm{CCl}_{4}$

$\mathrm{C}_{6} \mathrm{H}_{5} \mathrm{Cl}$

$\mathrm{CHCl}_{3}$

$\mathrm{C}_{6} \mathrm{H}_{12}$

$\mathrm{C}_{6} \mathrm{H}_{4} \mathrm{Cl}_{2}$ (ORTHO)

$\mathrm{C}_{6} \mathrm{H}_{4} \mathrm{Cl}_{2}$ (PARA)

$\mathrm{C}_{2} \mathrm{H}_{6} \mathrm{O}$

$\mathrm{C}_{8} \mathrm{H}_{10}$

$\mathrm{C}_{2} \mathrm{H}_{6} \mathrm{O}_{2}$

$\mathrm{Hg}$

$\mathrm{CH}_{4} \mathrm{O}$

$\mathrm{C}_{6} \mathrm{H}_{5} \mathrm{NO}_{2}$

$\mathrm{C}_{7} \mathrm{H}_{8}$

$\mathrm{C}_{6} \mathrm{H}_{3} \mathrm{Cl}_{3}$

$\mathrm{H}_{2} \mathrm{O}$

$\mathrm{C}_{8} \mathrm{H}_{10}$ (META)

$\mathrm{C}_{8} \mathrm{H}_{10}$ (ORTHO)

$\mathrm{C}_{8} \mathrm{H}_{10}$ (PARA)

CAS RN refers to the Chemical Abstracts Service Registry Number.

\section{DESCRIPTION OF MINERAL SUBSTRATES}

QUARTZ: The quartz crystals used in this series of measurements are from Pasto Bueno, Peru. They were subhedral crystals of the form of a prism truncated with a pyramid. The samples used for measurement purposes were pieces from the midst of the crystal, sawn perpendicular to the $C$-crystallographic axis. These surfaces were then lapped smooth with a diamond faced lapping wheel. One surface per sample was polished with ever decreasing grit sizes. The smallest grit used had a size of 0.3 microns.

CALCITE: The calcite crystals used in this series of measurements are from Mexico, but no exact location was available from the vendor. They are cleavage rhombs. One surface per rhomb was smoothed and polished as described in the section on quartz.

BIOTITE: The biotite samples were obtained from a pegmatite near Buffalo, Colorado. Fresh cleavage surfaces were used in this study. The biotite was split along parting planes $\{001\}$, to create the surfaces used. The surfaces were lightly polished with 0.3 micron grit to remove splinters which interfered with observation.

Ca-MONTMORILLONITE: The Ca-montmorillonite was obtained from the Clay Minerals Society Source Clay Minerals Repository and has the designation of STX-1. It is from Gonzales County, Texas, USA (Van Olphen and Fripiat, 1979). The clay was formed into a disk approximately $0.5 \mathrm{~cm}$ thick and $5.08 \mathrm{~cm}$ in diameter. The disk was prepared by 
placing 18.0 grams of dry clay into a cylinder stopped at one end by a polished, flat steel anvil and slowly compressed with a close fitting steel piston, with a polished, flat face. The compression process lasted one hour at room temperature $\left(19^{\circ} \mathrm{C}\right.$ to $\left.21^{\circ} \mathrm{C}\right)$ and achieved a pressure of twelve metric tons.

\section{EQUIPMENT}

The measurement apparatus used was a Rame-Hart model 100-00 Goniometer, a model 10010 micro-syringe attachment, and a Gilmont model S-1100 and S-1100A $2.0 \mathrm{ml}$ microsyringe.

\section{CALIBRATION}

The calibration sequence for the goniometer consisted of leveling the optical bench and specimen stage in accordance with the instruction manual (Rame-Hart, 1975), using a 24 inch and a 6 inch spirit level. The specimen platform was aligned to the optical axis of the magnifying optics by adjusting the specimen platform such that the edge of a flat glass slide laid flat upon the platform remained in the plane of the optic axis when it was placed in the front, back, right, or left edge of the specimen platform.

\section{CLEANING PROCEDURE}

The standard cleaning procedure depended on whether the liquid under investigation was water soluble or not. If the liquid was water soluble then the crystals were washed in a detergent solution of distilled water and International Products brand "Micro" laboratory cleaner. The surfaces were rubbed gently with a detergent saturated cotton swab. Biotite was not swabbed as cotton fibers would remain on the surface and interfere with measurements. The crystals were then rinsed with distilled water, placed on a paper towel to absorb the excess water, and air dried. If the liquid under investigation was not water soluble, then the crystal was first washed in ethanol to remove the majority of the liquid before being subjected to the above procedure. Thus the liquid and ethanol would be washed from the crystal's surface. Nitrobenzene and chloroform left residues that were not removed by standard washing techniques. In these cases, the quartz and calcite crystals were re-polished and new biotite specimens were cleaved and used. The Ca-montmorillonite disks were not cleaned as they were used for measurements with one liquid and discarded.

\section{EXPERIMENTAL PROCEDURE}

The goniometer was leveled at the beginning of the experimental procedure. It was checked twice during the course of measurements and no changes were observed.

One crystal each of calcite, quartz, and biotite sample had their mid-infrared spectra measured before each of the various liquids were applied. The surfaces of the various crystals were visually (x1) inspected prior to the application of any liquid. Any stain or contamination detected warranted a complete cleaning of the crystal. In the event that standard cleaning procedures were ineffective, the surface was re-polished.

The quartz and calcite crystals had their bases mounted in modelling clay. They were then placed in a hand press that made the upper and lower surfaces parallel to within $1^{\circ}(R$. Reynolds, oral communication, 1990). In this way, the upper surface of investigation was parallel to the specimen platform. Flat pieces of split biotite and the clay disks were placed directly on the specimen platform. 
The specimens were placed on the specimen platform and aligned. The syringe needle tip was brought to within approximately $7 \mathrm{~mm}$ of the crystal surface and individual drops were dispensed onto the crystal surface. These were the sessile drops. The static leading edge contact angle was observed and noted. The crystal was rotated to present a fresh surface for the next contact angle observation. Ten observations were normally taken on two crystals of each type. One clay disk was used per liquid.

Bringing the syringe needle tip to within 1 or $2 \mathrm{~mm}$ of the surface, so that the drop of liquid enveloped the tip was the instrument position used for observing advancing and receding contact angles: $\theta_{\mathrm{a}}$ and $\theta_{\mathrm{r}}$ respectively (Figure 2 ). The volume of the drop was increased using the micro-syringe and the angle at which the leading edge moved was observed and noted: $\theta_{\mathrm{a}}$. Reducing the drop's volume caused the trailing edge to recede. This contact angle was observed and noted: $\theta_{\mathrm{r}}$. The contact angle, by convention, is measured through the liquid (Good, 1979).

The advancing and receding contact angles for mercury could not be measured with the equipment available. However, since the hysteresis of liquid mercury is very low (Good, 1979) advancing and receding angles can be approximated by the sessile drop data.

Acetone evaporated so quickly from the surface of quartz that reliable advancing and receding angles could not be measured.

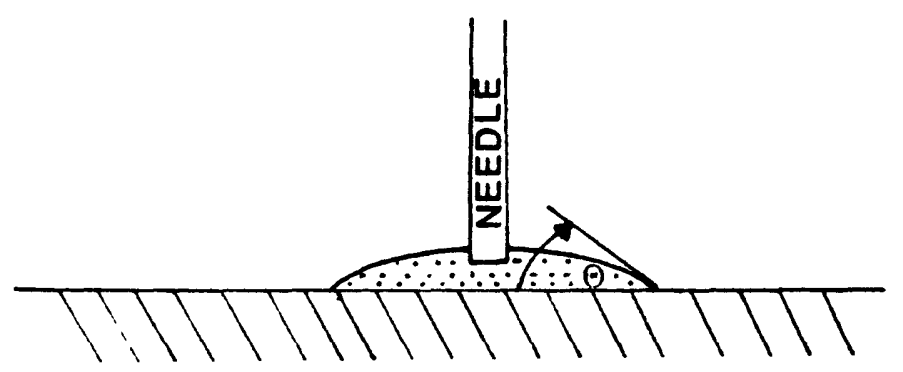

Figure 2. A schematic representation of a drop enveloping the dispensing needle. The advancing and receding contact angles are measured by increasing or decreasing the drop volume until the leading edge of the drop moves. A tangent drawn to the leading edge of an expanding drop measures $\theta_{\mathbf{a}}$, and to the trailing edge of a shrinking drop measures $\theta_{\mathbf{r}}$.

\section{DATA MANIPULATION}

The data for each liquid on each substrate had its highest and lowest value deleted. The mean and standard deviation of the remaining values were calculated.

\section{CONTACT ANGLE MEASUREMENTS}

In Tables 1, 2, and 3 on the following pages, the mean contact angle is reported plus or minus one standard deviation. Two crystals for each liquid and substrate were of ten measured and the results for each crystal are reported. 


\section{CONCLUSIONS AND RECOMMENDATIONS}

The mean advancing and receding contact angle measurements for a fluid on different crystals of the same substrate are repeatable usually within two degrees. Of the substrates used in this study, Ca-montmorillonite disks are the most easily wetted by a variety of liquids. This may be a function of the compressive force used in their fabrication. $\mathrm{Ca}$ montmorillonite does absorb and react, by swelling, with several of the liquids tested. The widest range of contact angles is exhibited on a calcite substrate: from $0^{\circ}$ to $66^{\circ}$, exclusive of mercury. This indicates that the ability of a liquid to move, by interfacial forces, through a calcite rich or cemented medium is very dependant on the liquid involved. The range of contact angles for liquids on biotite and quartz are intermediate between $\mathrm{Ca}$ montmorillonite and calcite. There is a very rough correlation between contact angle on quartz, calcite, and biotite and surface tension of the liquids: the higher the surface tension generally the higher the contact angle. The exception is water. It ranges from having the highest contact angle, after mercury, on quartz and $\mathrm{Ca}$-montmorillonite, and eighth lowest on biotite. Its behavior, in relation to other liquids, is the most strongly dependent on the substrate.

Methanol is the most wetting of the liquids tested. It completely wets quartz, calcite, and biotite, and reacts with $\mathrm{Ca}$-montmorillonite. Aniline is overall the least wetting organic liquid tested on quartz, calcite, and biotite. It does, however, totally wet Camontmorillonite. Mercury is the least wetting liquid studied on all substrates.

Even in relatively dry conditions, there exists a surface layer of water on mineral grains capable of conducting electrical charge. If the majority of mineral grains in a zone of relatively dry rock or soil are wetted by a non-conducting liquid, its presence may be detectable by electrical resistivity methods due to the displacement of water from the grain surfaces, and consequent resistivity increase.

Four mineral substrates and twenty-two liquids were tested in this study of contact angles in air. The wettability of the liquids on the substrates may be ranked either by advancing or receding angle on different substrates. A relative ranking of capillary pressures may also be calculated using the surface tensions and cosine of the contact angles. Other mineral substrates and liquids can be tested. Of particular interest are feldspar, clay, and other mineral substrates and other hazardous liquids. To complete the contact angle data set for Lucius, et al (1989), 32 more liquids need to be studied. Of these, 12 are extremely hazardous and will require elaborate personnel protection measures.

The situation where hazardous liquids are interacting interfacially with minerals in a dry environment has been partially addressed by this paper. The analogous situation in a water saturated environment has not. This needs to be studied to understand the interfacial processes occurring below the water table and what geophysical techniques can be employed to detect these hazardous liquids using this knowledge. 
Table 1 -- SESSILE DROP CONTACT ANGLE DATA

\begin{tabular}{|c|c|c|c|c|}
\hline FLUID/SUBSTRATE & QUARTZ & CALCITE & BIOTITE & CLAY \\
\hline ACETIC ACID & $\begin{array}{l}6 \pm 1^{0} \\
7 \pm 1^{0}\end{array}$ & $\begin{array}{l}22 \pm 7^{0} \\
25 \pm 5^{0}\end{array}$ & $\begin{array}{l}7+3^{0} \\
5+3^{\circ}\end{array}$ & $0^{0}$ \\
\hline ACETONE & $\begin{array}{l}6 \pm 1^{0} \\
4 \pm 3^{0}\end{array}$ & $\begin{array}{l}11 \pm 2^{0} \\
14 \pm 1^{0}\end{array}$ & $0^{0}$ & [1] \\
\hline ANILINE & $\begin{array}{l}41 \pm 1^{0} \\
38 \pm 1^{0}\end{array}$ & $\begin{array}{l}46 \pm 1^{0} \\
41 \pm 2^{\circ}\end{array}$ & $\begin{array}{l}38 \pm 3^{0} \\
41 \pm 2^{0}\end{array}$ & $0^{0}$ \\
\hline BENZENE & $\begin{array}{l}12 \pm 2^{0} \\
11 \pm 2^{0}\end{array}$ & $\begin{array}{l}18 \pm 2^{0} \\
25 \pm 2^{\circ}\end{array}$ & $10 \pm 4^{0}$ & $9+1^{0}$ \\
\hline CARBON TETRACHLORIDE & $\begin{array}{l}9 \pm 2^{0} \\
8 \pm 2^{\circ}\end{array}$ & $\begin{array}{l}13 \pm 3^{0} \\
14 \pm 2^{\circ}\end{array}$ & $\begin{array}{l}11 \pm 2^{0} \\
10 \pm 1^{0}\end{array}$ & $6 \pm 1^{0}$ \\
\hline CHLOROBENZENE & $\begin{array}{l}14 \pm 20 \\
16 \pm 20\end{array}$ & $\begin{array}{l}14 \pm 20 \\
18 \pm 20\end{array}$ & $\begin{array}{l}13 \pm 20 \\
17 \pm 30\end{array}$ & $5 \pm 10$ \\
\hline CHLOROFORM & $\begin{array}{l}8 \pm 1^{0} \\
8 \pm 1^{0}\end{array}$ & $\begin{array}{l}14 \pm 1^{0} \\
16 \pm 2^{0}\end{array}$ & $\begin{array}{l}8 \pm 1^{0} \\
8 \pm 2^{0}\end{array}$ & $7 \pm 2^{0}$ \\
\hline CYCLOHEXANE & $\begin{array}{l}9 \pm 1^{0} \\
8 \pm 1^{0}\end{array}$ & $\begin{array}{l}9 \pm 1^{0} \\
8 \pm 1^{0}\end{array}$ & $\begin{array}{l}7 \pm 2^{0} \\
7 \pm 2^{0}\end{array}$ & $7 \pm 1^{0}$ \\
\hline O-DICHLOROBENZENE & $\begin{array}{l}24 \pm 2^{0} \\
24 \pm 2^{\circ}\end{array}$ & $\begin{array}{l}30 \pm 1^{0} \\
26 \pm 3^{0}\end{array}$ & $\begin{array}{l}22 \pm 4^{0} \\
26 \pm 2^{0}\end{array}$ & $6 \pm 1^{0}$ \\
\hline p-DICHLOROBENZENE & $\begin{array}{l}23 \pm 2^{0} \\
23 \pm 1^{0}\end{array}$ & $\begin{array}{l}26 \pm 3^{0} \\
24 \pm 1^{0}\end{array}$ & $\begin{array}{l}22 \pm 3^{0} \\
24 \pm 1^{0}\end{array}$ & $5 \pm 1^{0}$ \\
\hline ETHANOL (denatured) & $0^{0}$ & $\begin{array}{l}9+1^{0} \\
18 \pm 3^{0}\end{array}$ & $0^{0}$ & [1] \\
\hline ETHYL BENZENE & $\begin{array}{l}12 \pm 3^{0} \\
9 \pm 2^{0}\end{array}$ & $\begin{array}{l}20 \pm 3^{0} \\
8 \pm 2^{0}\end{array}$ & $\begin{array}{l}12 \pm 2^{0} \\
9 \pm 3^{0}\end{array}$ & $6 \pm 1^{0}$ \\
\hline ETHYLENE GLYCOL & $\begin{array}{l}35 \pm 2^{0} \\
38 \pm 3^{0}\end{array}$ & $\begin{array}{l}72 \pm 5^{0} \\
61 \pm 3^{0}\end{array}$ & $\begin{array}{l}19 \pm 2^{0} \\
19 \pm 4^{0}\end{array}$ & $13 \pm 2^{0}$ \\
\hline MERCURY & $\begin{array}{l}136 \pm 3^{0} \\
138 \pm 3^{0}\end{array}$ & $\begin{array}{l}136 \pm 3^{0} \\
133 \pm 4^{0}\end{array}$ & $138 \pm 4^{0}$ & $158 \pm 6^{\circ}$ \\
\hline METHANOL & $0^{0}$ & $0^{0}$ & $0^{0}$ & [1] \\
\hline
\end{tabular}

[1] The liquid caused the clay to quickly swell and the contact angle could not be accurately measured. 
Table 1 (cont.)

FLUID/SUBSTRATE

QUARTZ CALCITE BIOTITE CLAY

NITROBENZENE

$\begin{array}{ll}33 \pm 3^{\circ} & 39 \pm 3^{\circ} \\ 34 \pm 3^{\circ} & 34 \pm 3^{\circ}\end{array}$

TOLUENE

$9 \pm 1^{0} \quad 13 \pm 2^{0}$

$9 \pm 1^{0}$

$15 \pm 1^{\circ}$

$12 \pm 2^{0}$

$5 \pm 1^{0}$

1, 2, 4-TRICHLOROBENZENE

$28 \pm 5^{\circ}$

$36 \pm 4^{0}$

$23 \pm 2^{\circ}$

$28 \pm 5^{\circ}$

$29 \pm 1^{\circ}$

$6 \pm 1^{0}$

WATER

$29 \pm 30$

$42 \pm 1^{\circ}$

$40 \pm 8^{\circ}$

$44 \pm 5^{\circ}$

$9 \pm 2^{\circ}$

$22 \pm 3^{0}$

m-XYLENE

$6 \pm 1^{\circ}$
$4 \pm 1^{\circ}$

$8 \pm 2^{0}$

$4 \pm 10$

$11 \pm 3^{0}$

$10 \pm 1^{\circ}$

[1]

O-XYLENE

$9 \pm 1^{0}$
$7 \pm 1^{\circ}$

$12 \pm 2^{0}$

$12 \pm 3^{\circ}$

$12 \pm 3^{\circ}$

[1]

$5 \pm 1^{0}$
$5 \pm 1^{\circ}$

$6 \pm 2^{0}$
$7 \pm 1^{\circ}$

$11 \pm 2^{0}$
$5 \pm 1^{\circ}$

$5 \pm 1^{0}$

p-XYLENE

[1] The liquid caused the clay to quickly swell and the contact angle could not be accurately measured. 
Table 2 -- ADVANCING ANGLES $\left(\theta_{9}\right)$

FLUID/SUBSTRATE

ACETIC ACID

ACETONE

ANILINE

BENZENE

CARBON TETRACHLORIDE

CHLOROBENZENE

CHLOROFORM

CYCLOHEXANE

O-DICHLOROBENZENE

p-DICHLOROBENZENE

ETHANOL

ETHYLBENZENE

ETHYLENE GLYCOL

METHANOL

\section{QUARTZ}

$12 \pm 1^{0}$
$12 \pm 1^{\circ}$

[2]

2]

$38 \pm 4^{\circ}$

$38 \pm 1^{\circ}$

$18 \pm 2^{\circ}$

$16 \pm 3^{\circ}$

$12 \pm 2^{0}$

$12 \pm 1^{\circ}$

$12 \pm 1^{\circ}$

$14 \pm 1^{\circ}$

$11 \pm 1^{0}$
$11+1^{0}$

$12+1^{\circ}$

$11 \pm 1^{\circ}$

$24 \pm 2^{\circ}$

$26 \pm 2^{\circ}$

$22 \pm 3^{\circ}$

$22 \pm 1^{\circ}$

$0^{0}$

$13 \pm 1^{\circ}$
$14 \pm 1^{\circ}$

$31 \pm 2^{0}$

$36 \pm 4^{0}$

$0^{\circ}$
CAlCite Biotite

CLAY

$31 \pm 3^{0}$

$30 \pm 3^{0}$

$16 \pm 2^{\circ}$

$14 \pm 2^{\circ}$

$48 \pm 2^{\circ}$

$43 \pm 2^{\circ}$

$10 \pm 5^{0}$

$12 \pm 3^{\circ}$

$0^{\circ}$

[1]

$23 \pm 3^{0}$

$26 \pm 1^{\circ}$

$18 \pm 1^{\circ}$

$17 \pm 2^{0}$

$15 \pm 3^{\circ}$

$20 \pm 2^{\circ}$

$21 \pm 3^{0}$

$15 \pm 2^{0}$

$12 \pm 1^{\circ}$

$11 \pm 1^{0}$

$32 \pm 3^{\circ}$

$30+2^{\circ}$

$25+2^{\circ}$

$24 \pm 1^{\circ}$

$0^{13 \pm 2^{0}}$

$43 \pm 3^{\circ}$

$41 \pm 3^{0}$

$19 \pm 1^{0}$

[1]

$14 \pm 1^{0}$

$11 \pm 1^{\circ}$

$9 \pm 1^{0}$

$16 \pm 1^{0}$

$17 \pm 2^{\circ}$

$10 \pm 1^{0}$

$1 \pm 2^{0}$

$12 \pm 1^{\circ}$

[1]

$10 \pm 2^{\circ}$

$10 \pm 1^{\circ}$

$10 \pm 1^{0}$

$22 \pm 1^{0}$

$23 \pm 4^{\circ}$

$24 \pm 4^{\circ}$

$27 \pm 1^{\circ}$

$0^{0}$

$0^{0}$

$\begin{array}{ll}18 \pm 2^{\circ} & 14 \pm 2^{\circ} \\ 11 \pm 2^{\circ} & 12 \pm 3^{\circ}\end{array}$

[1]

$66 \pm 4^{\circ} \quad 24 \pm 3^{\circ}$

$64 \pm 4^{\circ} \quad 27 \pm 11^{\circ}$

$14 \pm 2^{\circ}$

$0^{\circ}$

$0^{\circ}$

$6 \pm 1^{0}$

$8 \pm 1^{0}$

$14 \pm 2$

$0^{0}$

[1] The liquid caused the clay to quickly swell and the contact angle could not be accurately measured.

[2] Rapid evaporation at the drop's edge prevented accurate angle measurement. 
Table 2 (cont.)

FLUID/SUBSTRATE

QUARTZ CALCITE BIOTITE CLAY

NITROBENZENE

$30+2$

$33 \pm 3^{0}$

$32 \pm 3^{0}$

$30 \pm 6^{0}$

$12 \pm 1^{0}$

$32 \pm 2^{\circ}$

$16 \pm 2^{0}$

$15 \pm 3^{\circ}$

$15 \pm 1^{0}$

[1]

$11 \pm 1^{\circ}$

$33+2^{\circ}$

$27 \pm 2^{0}$

$\begin{array}{ll}27 \pm 2^{\circ} & 33 \pm 4^{\circ} \\ 46 \pm 4^{\circ} & 11 \pm 2^{\circ}\end{array}$

$9 \pm 1^{0}$

WATER

$28 \pm 1^{\circ}$

$39 \pm 4^{0}$

$41 \pm 3^{\circ}$

$48 \pm 5^{\circ}$

[1]

m-XYLENE

$7 \pm 1^{0}$
$8 \pm 1^{\circ}$

$14 \pm 1^{0}$

$10 \pm 2^{0}$

$8 \pm 2^{\circ}$

[1]

$10 \pm 1^{0} \quad 11+2^{\circ}$

$9 \pm 1^{\circ}$

o-XYLENE

$10 \pm 1^{0}$

$11 \pm 1^{\circ}$

$12 \pm 2^{\circ}$

$13 \pm 2^{\circ}$

[1]

$7 \pm 1^{0}$
$8 \pm 1^{0}$

$7 \pm 1^{0}$
$8+2^{0}$

$10 \pm 2^{0}$

$9+1^{0}$

$7 \pm 1^{0}$

[1] The liquid caused the clay to quickly swell and the contact angle could not be accurately measured. 
Table 3 - RECEDING ANGLES $\left(\theta_{\text {I }}\right)$

\begin{tabular}{|c|c|c|c|c|}
\hline FLUID/SUBSTRATE & QUARTZ & CALCITE & BIOTITE & CLAY \\
\hline ACETIC ACID & $\begin{array}{l}3 \pm 1^{0} \\
4 \pm 1^{0}\end{array}$ & $\begin{array}{l}17 \pm 2^{0} \\
19 \pm 4^{0}\end{array}$ & $0^{0}$ & $0^{0}$ \\
\hline ACETONE & [2] & $\begin{array}{l}6 \pm 1^{0} \\
5 \pm 1^{0}\end{array}$ & $0^{0}$ & [1] \\
\hline $\begin{array}{l}\text { ANILINE } \\
\text { BENZENE }\end{array}$ & $\begin{array}{l}24 \pm 1^{0} \\
25 \pm 1^{0} \\
6 \pm 1^{0} \\
6 \pm 1^{0}\end{array}$ & $\begin{array}{l}30 \pm 2^{0} \\
26 \pm 2^{0} \\
9 \pm 1^{0} \\
10 \pm 1^{0}\end{array}$ & $\begin{array}{l}24 \pm 2^{0} \\
21 \pm 2^{0} \\
7 \pm 3^{0}\end{array}$ & $\begin{array}{l}0^{0} \\
{[1]}\end{array}$ \\
\hline CARBON TETRACHLORIDE & $\begin{array}{l}8 \pm 1^{0} \\
7 \pm 1^{0}\end{array}$ & $\begin{array}{l}9 \pm 1^{0} \\
11 \pm 1^{0}\end{array}$ & $\begin{array}{l}8 \pm 1^{0} \\
9 \pm 1^{0}\end{array}$ & $6 \pm 1^{0}$ \\
\hline CHLOROBENZENE & $\begin{array}{l}6 \pm 1^{0} \\
6 \pm 1^{0}\end{array}$ & $\begin{array}{l}8 \pm 1^{0} \\
8 \pm 2^{0}\end{array}$ & $\begin{array}{l}6 \pm 1^{0} \\
8 \pm 1^{0}\end{array}$ & $0^{0}$ \\
\hline CHLOROFORM & $\begin{array}{l}8 \pm 1^{0} \\
8 \pm 2^{0}\end{array}$ & $\begin{array}{l}5 \pm 1^{0} \\
8 \pm 3^{0}\end{array}$ & $\begin{array}{l}9 \pm 2^{0} \\
10 \pm 1^{0}\end{array}$ & {$[1]$} \\
\hline CYCLOHEXANE & $\begin{array}{l}8 \pm 1^{0} \\
7 \pm 1^{0}\end{array}$ & $\begin{array}{l}9 \pm 1^{0} \\
9 \pm 1^{0}\end{array}$ & $\begin{array}{l}7 \pm 2^{0} \\
7 \pm 1^{0}\end{array}$ & $9 \pm 2^{0}$ \\
\hline o-DICHLOROBENZENE & $\begin{array}{l}16 \pm 2^{0} \\
18 \pm 3^{0}\end{array}$ & $\begin{array}{l}11 \pm 2^{0} \\
10 \pm 2^{0}\end{array}$ & $\begin{array}{l}11 \pm 2^{0} \\
10 \pm 2^{0}\end{array}$ & $0^{0}$ \\
\hline p-DICHLOROBENZENE & $\begin{array}{l}14 \pm 3^{0} \\
13 \pm 3^{0}\end{array}$ & $\begin{array}{l}13 \pm 2^{0} \\
15 \pm 2^{0}\end{array}$ & $\begin{array}{l}13 \pm 5^{0} \\
16 \pm 4^{0}\end{array}$ & $5 \pm 1^{0}$ \\
\hline ETHANOL & $0^{0}$ & $0^{0}$ & $0^{0}$ & [1] \\
\hline ETHYL BENZENE & $\begin{array}{l}5 \pm 1^{0} \\
7 \pm 1^{0}\end{array}$ & $\begin{array}{l}7 \pm 2^{0} \\
5 \pm 1^{0}\end{array}$ & $\begin{array}{l}5 \pm 1^{0} \\
6 \pm 2^{0}\end{array}$ & [1] \\
\hline ETHYLENE GLYCOL & $\begin{array}{l}4 \pm 1^{0} \\
5 \pm 3^{0}\end{array}$ & $\begin{array}{l}36 \pm 7^{0} \\
32 \pm 6^{0}\end{array}$ & $\begin{array}{l}4 \pm 1^{0} \\
5 \pm 1^{0}\end{array}$ & $0^{0}$ \\
\hline METHANOL & $0^{0}$ & $0^{0}$ & $0^{0}$ & $0^{0}$ \\
\hline
\end{tabular}

[1] The liquid caused the clay to quickly swell and the contact angle could not be accurately measured.

[2] Rapid evaporation at the drop's edge prevented accurate angle measurement. 
Table 3 (cont.)

FLUID/SUBSTRATE

QUARTZ CALCITE BIOTITE CLAY

NITROBENZENE

$19 \pm 2^{\circ} \quad 14 \pm 2^{\circ}$

$17 \pm 1^{0}$

$16 \pm 1^{\circ}$

TOLUENE

$7 \pm 1^{0}$
$7 \pm 1^{0}$

$\frac{5 \pm 1^{0}}{6 \pm 1^{0}}$

[1]

1, 2, 4-TRICHLOROBENZENE

$17 \pm 3^{0}$

$21 \pm 1^{\circ}$

$16 \pm 1^{\circ}$

$12 \pm 2^{\circ}$

$8 \pm 4^{0}$

$14 \pm 5^{0}$

$5 \pm 1^{\circ}$

WATER

$8 \pm 1^{0}$

$6 \pm 1^{0}$

$0^{0}$

[1]

$10 \pm 1^{0}$

$8 \pm 2^{\circ}$

m-XYLENE

$3 \pm 1^{0}$
$4+2^{0}$

$5 \pm 1^{0}$

$3 \pm 2^{0}$
$2 \pm 1^{0}$

[1]

O-XYLENE

$6 \pm 1^{0}$
$7 \pm 1^{\circ}$

$4 \pm 1^{0}$

$6+2^{0}$

$7 \pm 1^{0}$

[1]

p-XYLENE

$0^{0}$

$17 \pm 2^{\circ}$

$0^{\circ}$

$0^{0}$

[1] The liquid caused the clay to quickly swell and the contact angle could not be accurately measured. 


\section{QUARTZ}

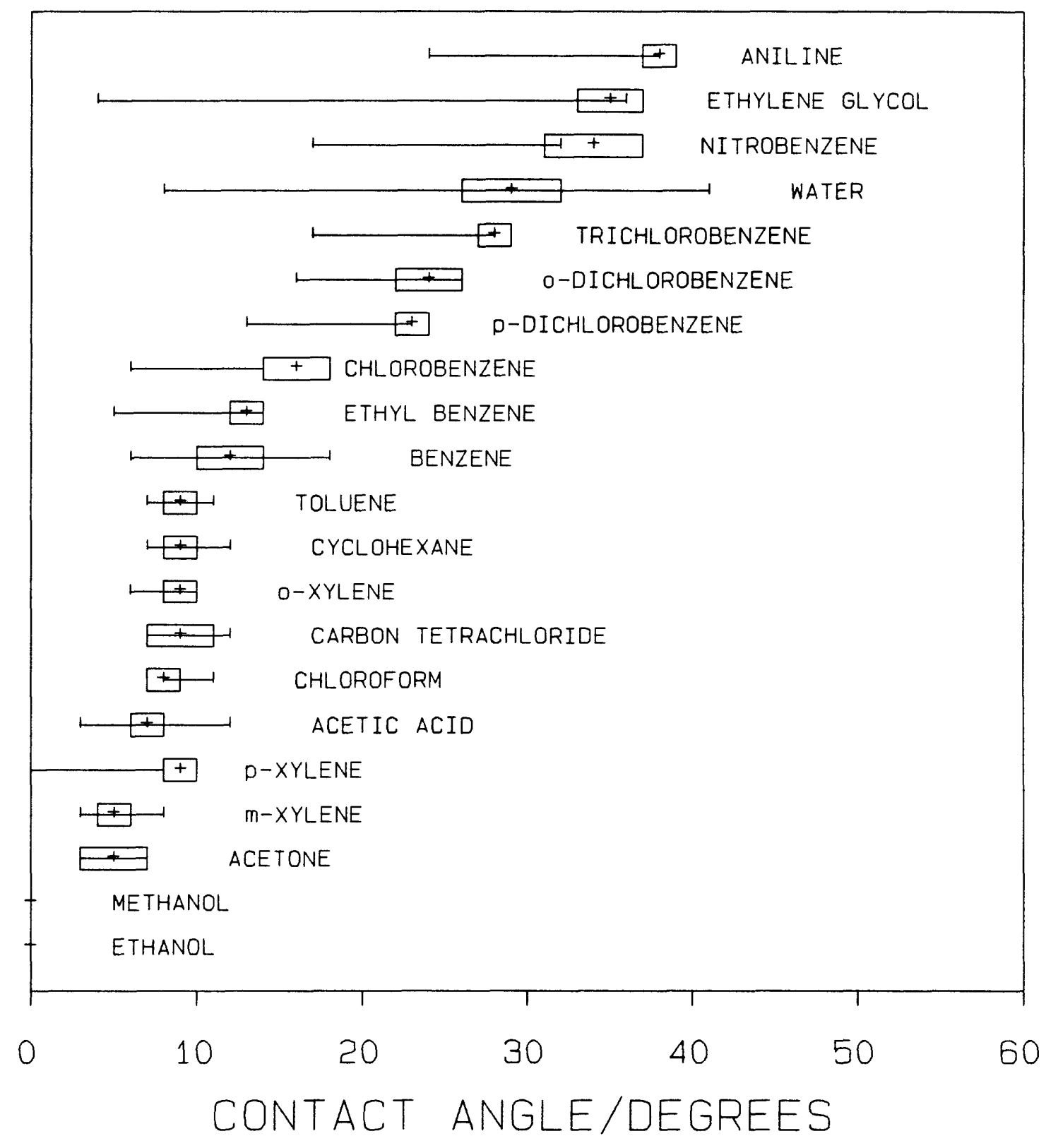

Figure 3. The data sorted by sessile contact angle. The "+" represents the sessile drop angle and the enclosing box is plus or minus one standard deviation. The range bar represents the receding (left end) and advancing (right end) angles. Smaller angles indicate better wetting on a quartz substrate. 


\section{CALCITE}

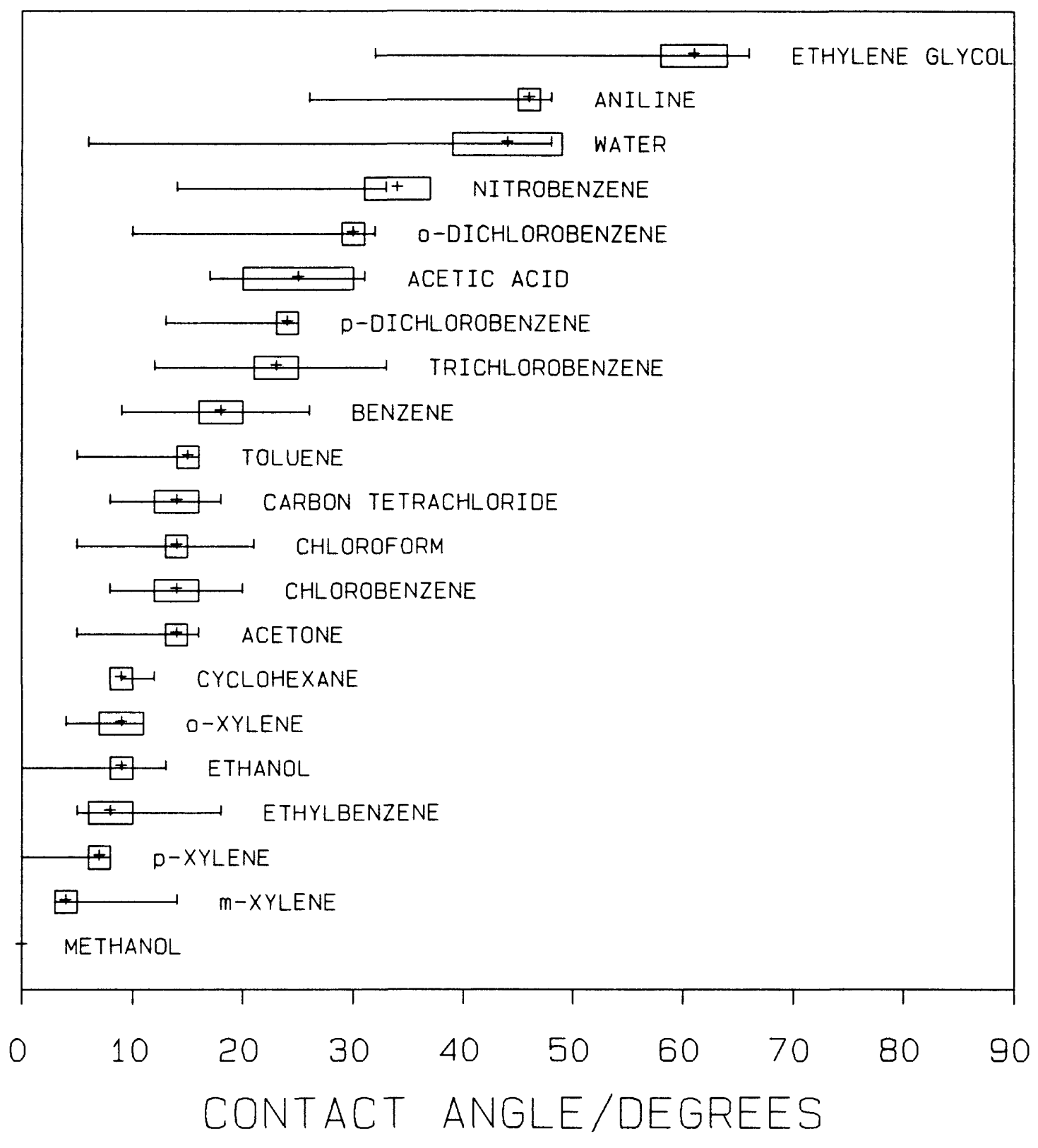

Figure 4. The data sorted by sessile contact angle. The " + " represents the sessile drop angle and the enclosing box is plus or minus one standard deviation. The range bar represents the receding (left end) and advancing (right end) angles. Smaller angles indicate better wetting on a calcite substrate. 


\section{BIOTITE}

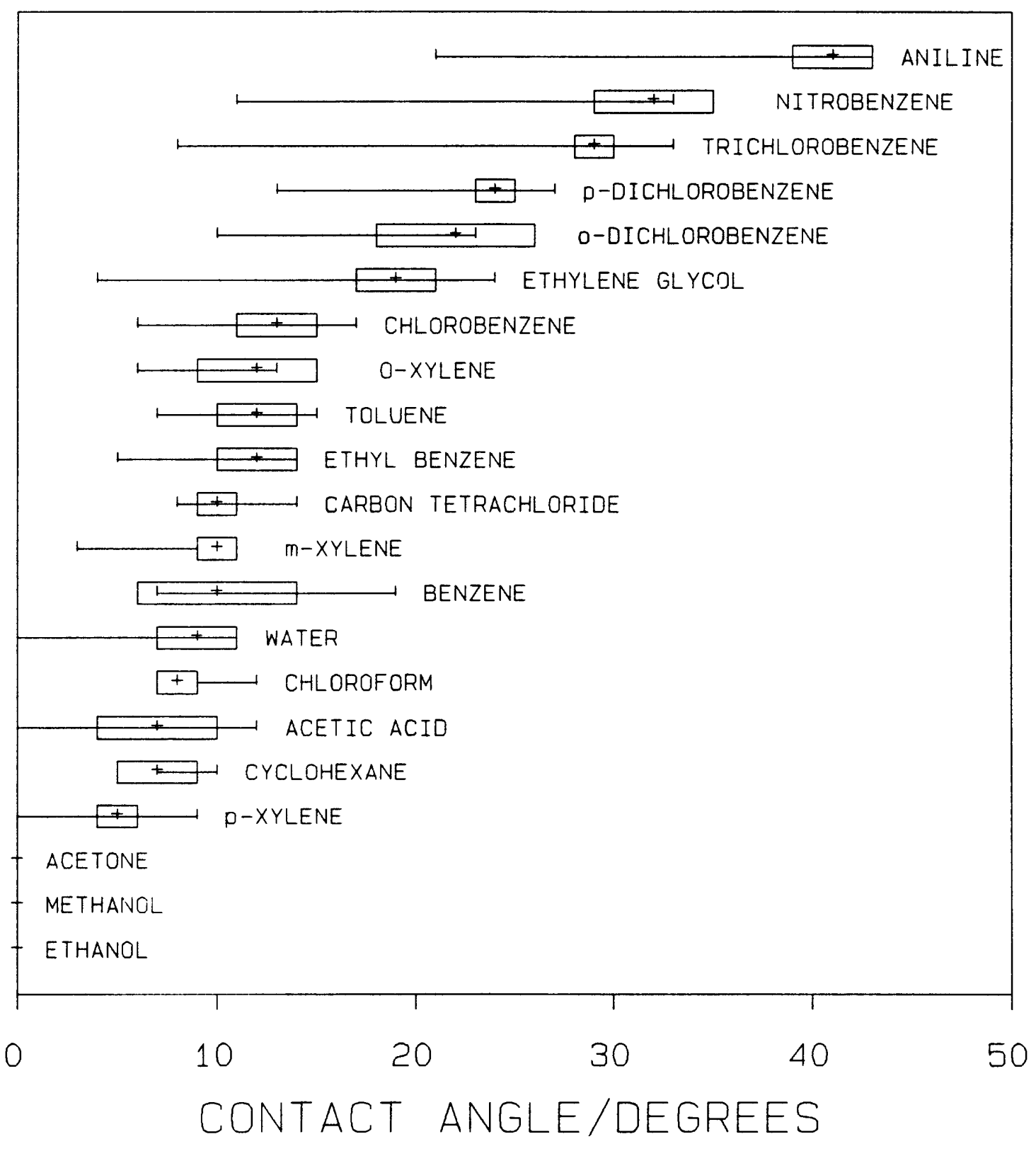

Figure 5. The data sorted by sessile contact angle. The " $+"$ represents the sessile drop angle and the enclosing box is plus or minus one standard deviation. The range bar represents the receding (left end) and advancing (right end) angles. Smaller angles indicate better wetting on a biotite substrate. 


\section{Ca-MONTMORILLONITE}

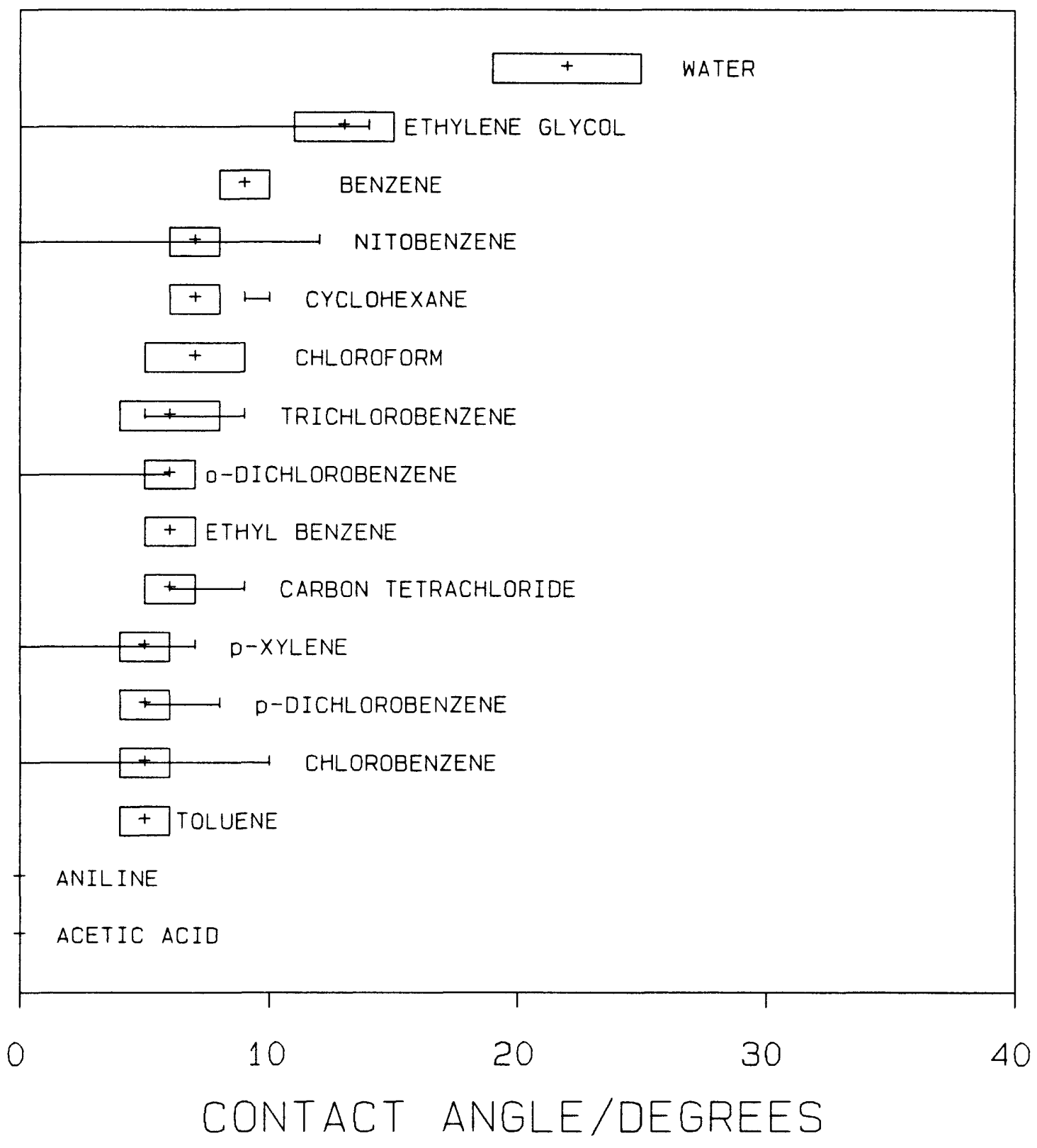

Figure 6. The data sorted by sessile contact angle. The " + " represents the sessile drop angle and the enclosing box is plus or minus one standard deviation. The range bar represents the receding (left end) and advancing (right end) angles. Smaller angles indicate better wetting on a $\mathrm{Ca}$-montmorillonite substrate. 


\section{REFERENCES}

Bear, J. and Verruijt, A., 1987, Modeling groundwater flow and pollution, Boston, D. Reidel Publishing Company, 414p.

Good, R. J., 1979, Contact angles and surface free energy of solids, in Surface and colloid science Vol. 11, R. J. Good and R. R. Stromberg eds., New York, Plenum Press.

Lucius, J. E., Olhoeft, G. R., Hill, P. L., and Duke, S. K., 1989, Properties and hazards of 108 selected substances, U. S. Geological Survey Open-File Report 89-491, 538p.

Rame-Hart, Inc, circa 1975, Instruction manual: contact angle goniometers, Mountain Lakes, New Jersey, Rame-Hart, Inc., 27p.

Van Olphen, H. and Fripiat, J. J., 1979, Data handbook for clay materials and other nonmetallic minerals, NY, Pergamon Press, 364p. 